\title{
The Impact of Different Terrain Configurations on the Formation and Dynamics of Katabatic Flows: Idealised Case Studies
}

\author{
K. Trachte - T. Nauss - J. Bendix
}

Received: 28 January 2009 / Accepted: 2 November 2009 / Published online: 28 November 2009

(C) The Author(s) 2009. This article is published with open access at Springerlink.com

\begin{abstract}
Impacts of different terrain configurations on the general behaviour of idealised katabatic flows are investigated in a numerical model study. Various simplified terrain models are applied to unveil modifications of the dynamics of nocturnal cold drainage of air as a result of predefined topographical structures. The generated idealised terrain models encompass all major topographical elements of an area in the tropical eastern Andes of southern Ecuador and northern Peru, and the adjacent Amazon. The idealised simulations corroborate that (i) katabatic flows develop over topographical elements (slopes and valleys), that (ii) confluence of katabatic flows in a lowland basin with a concave terrainline occur, and (iii) a complex drainage flow system regime directed into such a basin can sustain the confluence despite varying slope angles and slope distances.
\end{abstract}

Keywords Confluence $\cdot$ Katabatic flows - Numerical simulation - Terrain configuration

\section{Introduction}

Katabatic flows are atmospheric boundary-layer phenomena that form in hilly and mountainous regions worldwide. They develop on calm, clear nights by radiative cooling of the surface, generating a horizontal temperature gradient to the ambient air at the same height. Wind speed is conditioned by the cooling rates and the vertical temperature gradient, the surface roughness and the angle of elevation. Therefore the atmospheric conditions, the surface characteristics (i.e. the current land cover) as well as the terrain represent the essential factors that affect the development of katabatic flows (Prandtl 1942; Defant 1949; Shapiro and Fedorovich 2007).

K. Trachte $(\varangle) \cdot$ J. Bendix

Laboratory for Climatology and Remote Sensing (LCRS), Faculty of Geography, University of Marburg, Marburg, Germany

e-mail: trachtek@staff.uni-marburg.de

T. Nauss

Climatology, University of Bayreuth, Bayreuth, Germany 


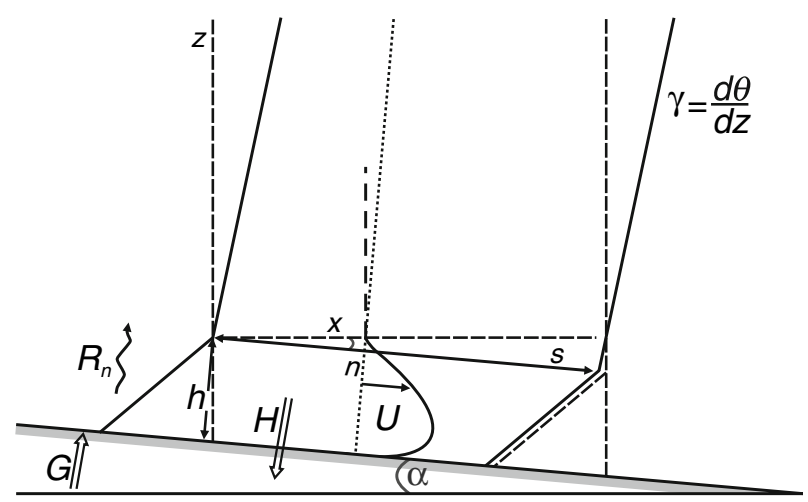

Fig. 1 Schematic of an idealised katabatic flow (after Manins 1992)

Figure 1 shows an idealised flow along a slope with an angle $\alpha$ (after Manins 1992). As a result of longwave emission into the atmosphere a sensible heat flux $H$ from the atmospheric boundary layer towards the surface develops, cooling the air. This radiative divergence $\left(R_{n}\right)$ associated with the heat fluxes $(H)$ into the ground leads to the development of an inversion with depth $h$. In addition, horizontal temperature and pressure gradients are generated between the ambient air over the slope and the air away from the slope at the same height. As a consequence of this horizontal density difference a downslope motion $U$ of cold air as a function of the angle $\alpha$ and the slope distance occurs. The flow starts with the typical jet-like profile and persists by steady cooling of the surface layer, sustaining the density gradient and creating a buoyancy deficit. The shape of the wind profile results from ground friction retarding the streaming air directly over the ground and a pressure gradient decreasing with increasing height in the inversion layer $h$.

Because of their drainage effect, katabatic flows ensure an efficient nocturnal ventilation of the slopes. Normally, they affect local weather by inducing a stabilisation of the atmosphere within the nocturnal boundary layer, which has been consistently examined over the last few decades (Fleagle 1950; Thyer 1966; Gutman 1983; Smith and Skyllingstad 2005; Yu and Cai 2006; Poulos et al. 2007). Such investigations comprised measurement campaigns as well as model studies for a better comprehension of their characteristics and more realistic prediction of their occurrence. Horst and Doran (1986) investigated the initial phase of nocturnal slope flows in the Geysers Geothermal Resource Area of northern California with different topography and vegetation. Clements et al. (1989) showed the mean structure of the drainage flow down the Brush Creek valley of western Colorado. Skyllingstad (2003) used a large-eddy simulation model to study the structure and evolution of katabatic flows over simple slopes. For the current study, the impact of different topographical geometries on the formation and dynamics of katabatic flows is examined. For this reason, two different areas are of interest: the eastern Andes of southern Ecuador and the adjacent Peruvian Amazon (see Fig. 2 right).

In the Andean highlands Bendix et al. (2006) found a nocturnal rainfall maximum in the Rio San Francisco Valley (ECSF (Estacion Cientifica San Francisco) in Fig. 2). Precipitation measurements from automatic climate stations and vertical pointing rain radar revealed a significant and quite constant early morning rainfall maximum within this study area. An analysis of corresponding GOES satellite imagery shows the nocturnal formation of mesoscale convective systems (MCS) in the second region, the Andean foothills southeast of the Rio San Francisco Valley (Fig. 2) (Bendix et al. 2009). It was hypothesised that the generation of the cloud cluster and, thus, the nocturnal rainfall on the slopes could be 


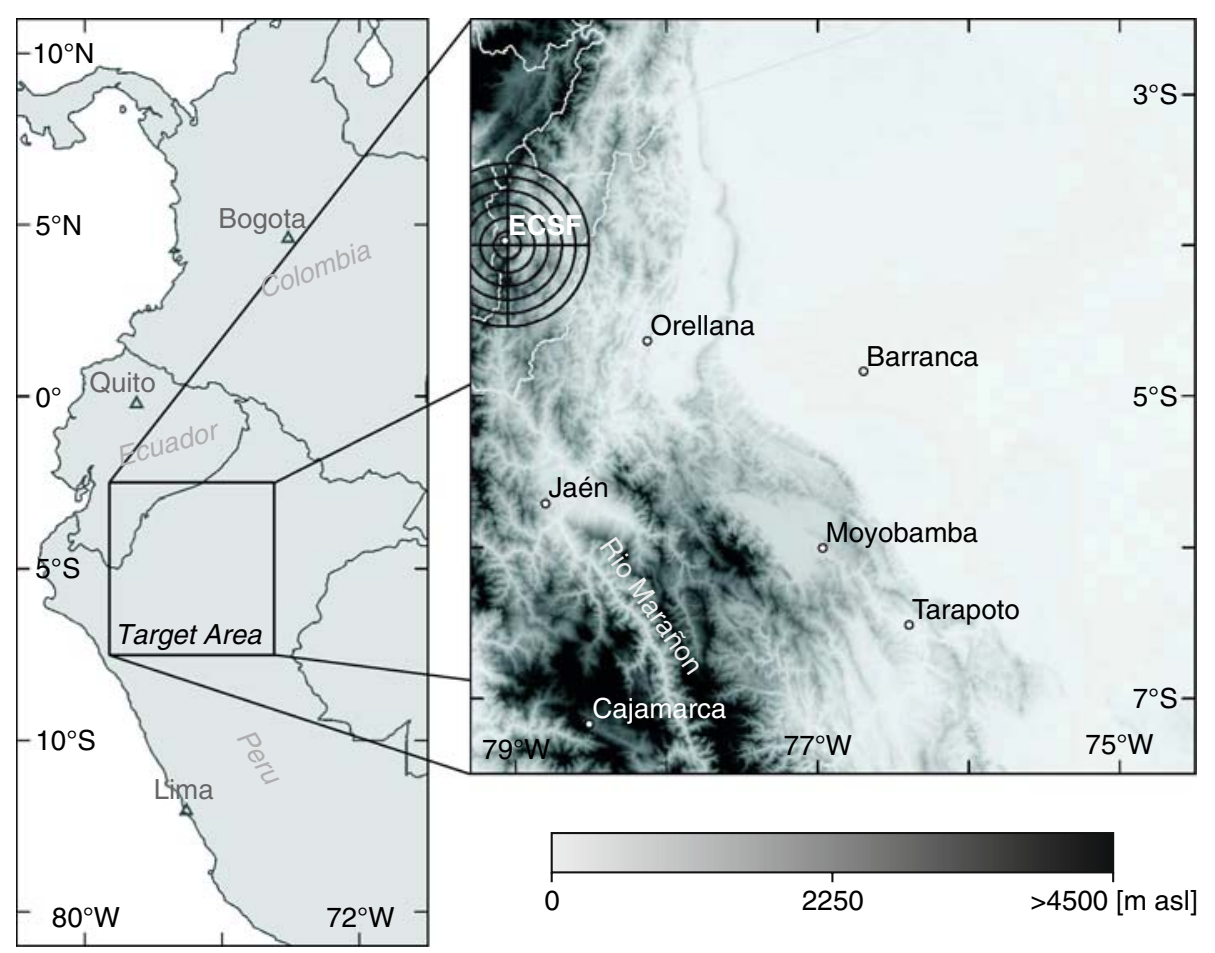

Fig. 2 Study area (left), target area (right) with coverage of the local area weather radar

associated with nocturnal cold air drainage flow from the Andean slopes and valleys: (i) The cold air confluences due to the concave-shaped Andean terrain in the foothill region, (ii) where it converges with the warm moist air of the Amazon basin. This process could lead to low-level instabilities and to the formation of the MCS. Here, we attempt the analysis of the first process of the hypothesis stated above, i.e. the analysis of the influence of different terrain shapes on the occurrence of idealised katabatic flows with special interest in their lowland confluence. The geometry of the topography exerts a strong effect on the general behaviour of the flow; with a concave lined slope the air is forced to confluence indicated by an additional mass contribution.

Due to unavailable measurements in the cloud formation region, the most appropriate tools to disentangle these processes are numerical models. The development of models to simulate katabatic flow systems extends from linear hydraulic models (Ball 1956; Manins and Sawford 1979; Mahrt 1982; Fitzjarred 1984; Kondo and Sato 1988) to numerical model studies considering the development and the forecast of the flow (Garrett 1983; Lalaurette and Andre 1985; Doran 1990b; Heilman and Takle 1991; Gudiksen et al. 1992).

In this study, a numerical model has been used to examine, (i) the confluence of the flow with a uniform concave lined terrain shape, and (ii) the impact of a drainage system on the confluence considering the orographical situation in the second study area. To do so, simplified terrain models are used, which highlight the main features of the real terrain while simultaneously avoiding, for example, very steep valleys leading to problems in the wind field computation (Chow et al. 2006). Since the Peruvian east Andean slopes of the target area consist of an irregular ridgeline forming a concave shaped basin carved by several 
valleys, the most complex terrain model also consists of a basin with surrounding mountain tops and draining valleys with special reference to lowland cold air confluence. In addition, less complex terrains are used in our study to analyse the principle alteration of momentum and energy fluxes due to an evolving katabatic flow. By increasing the complexity of the terrain models between the different simulation runs, the role of different orographic features on the development of katabatic flows and their impact on the structure and propagation of the flow can be revealed.

The next section gives an overview of the model set-up and the idealised terrain models. Afterwards, the different idealised profiles demonstrate their impact on the general flow dynamics concerning a lowland confluence of cold air due to a concave terrain configuration.

\section{Model Set-up}

The Advanced Regional Prediction System mesoscale model (ARPS) was used to analyse the impact of different terrain shapes on the dynamics of idealised katabatic flows. ARPS was developed at the Center for Analysis and Prediction of Storms (CAPS) at the University of Oklahoma, and is a three-dimensional, non-hydrostatic model with a generalised terrainfollowing coordinate system and a vertically stretched grid. For more details, see Xue et al. $(1995,2000,2001)$. The idealised simulations of the katabatic flows are calculated on two different domains: three runs using a domain with $120 \times 120$ grid points and another two runs using a domain with $402 \times 402$ grid points. Both domains have a horizontal resolution of $250 \mathrm{~m}$. The vertical grid was stretched with a hyperbolic function, with a resolution of $10 \mathrm{~m}$ near the ground and $500 \mathrm{~m}$ at the top of the domain. In the lower domain, 30 of the 55 vertical layers are located to engage the development of a downslope motion in the nocturnal boundary layer.

\subsection{Topography}

In order to analyse the effects of various topographical geometries on the behaviour of the propagation of katabatic flows, the main features of the target area have been simplified. Therefore, five simplified terrain configurations with increasing complexity have been used (Fig. 3). The basic topography to simulate katabatic flows is a simple slope (Fig. 3a), it is used to demonstrate the essential characteristics inducing a downslope flow, i.e. the vertical temperature distribution, the wind field, the net radiation and the surface fluxes. The slope angle $\alpha$ has a value of approximately $5^{\circ}$. By mirroring the simple slope, a simple valley is generated, leading to an accumulation of the cold drainage air in the valley floor (Fig. 3b). Drainage of the accumulated air is obtained by creating an additional along-valley inclination angle $\beta$ of approximately $1^{\circ}$ (Fig. 3c). Thus, besides the cross-valley flows, the alongvalley flow draining the cold air into the basin can be represented. To examine the confluence of katabatic flows as a result of a topographical shape, a terrain model forming a uniform concave ridgeline was used (Fig. 3d). The slope angle $\alpha$ is close to the previous terrain models. With this orographical shaping, the general behaviour concerning the confluence is disclosed. Since the eastern slopes of the Ecuadorian/Peruvian Andes in the target area shown in Fig. 2 form a quasi-concave shaped basin surrounded by several mountain tops and draining valleys, the most complex terrain model consists of a concave ridgeline carved by several valleys (Fig. 3e). They form an extensive drainage system directed towards the basin, and enables the analysis of both the inflow of cold air into the basin due to the valleys and its confluence. 


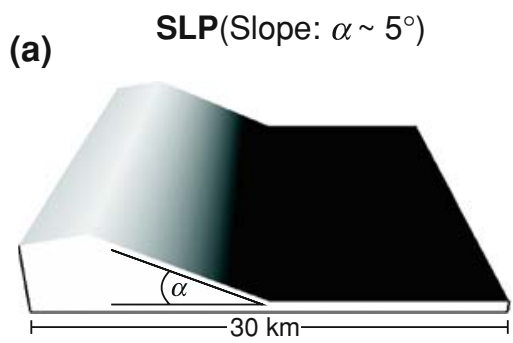

VAL(Valley)

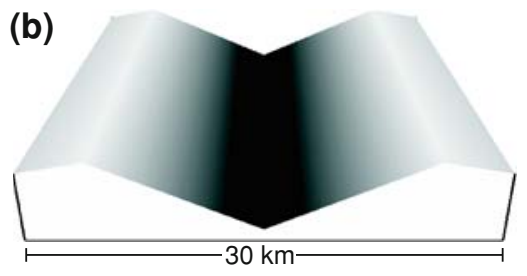

BSN(Basin: $\alpha \sim 5^{\circ}$ )

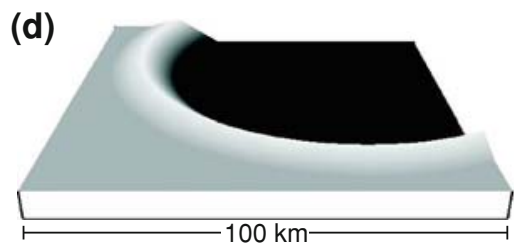

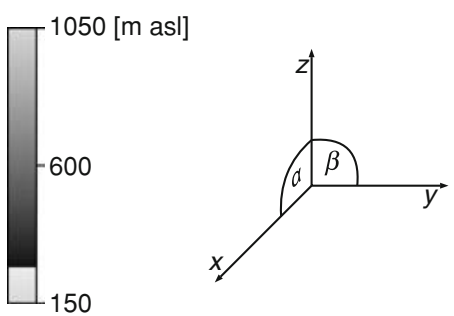

VAL2(VAL with $\beta \sim 1^{\circ}$ )
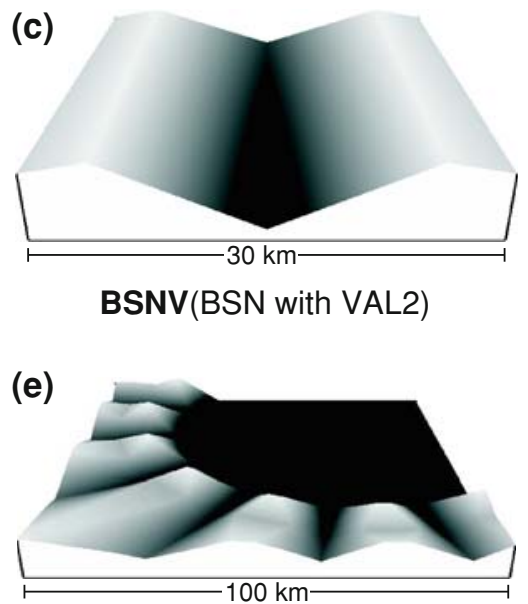

Fig. 3 Simplified terrain models: a simple uniform slope (SLP), b simple uniform valley (VAL), c simple valley with an additional along-valley height gradient (VAL2), $\mathbf{d}$ basin (BSN), e basin with a drainage system (BSNV)

\subsection{Initialisation and Boundary Conditions}

The initial values for the atmospheric conditions representing the situation at sunset are provided by an idealised sounding, and are derived from a tropical model atmosphere (McClatchey et al. 1972), and adjusted with an approximately neutral temperature stratification in the lower atmosphere and a lightly stable profile in the upper atmosphere. The initial potential temperature starts with $300 \mathrm{~K}$ at the surface and increases by $0.5 \mathrm{~K} \mathrm{~km}^{-1}$ up to a height of $3000 \mathrm{~m}$. Above this level, the potential temperature increases by $4 \mathrm{~K} \mathrm{~km}^{-1}$. To avoid any stream flows overlaying the thermally induced flow at the beginning of the simulation, the wind field is set to zero. Water was considered in the simulation for the calculation of the surface fluxes only. The boundary conditions of each domain have been set to a rigid wall at the top with a damping layer at two-thirds of the atmosphere with five friction absorbing layers to prevent unrealistic reflection. At the lateral boundaries, open radiation conditions with the Klemp and Wilhelmson type (Klemp and Wilhelmson 1978) for the constant phase speed, which is computed and applied at each timestep on the four lateral sides, have been used. 


\subsection{Physics}

ARPS was used with the following physics packages: for the turbulence parametrisation the 1.5-order turbulent kinetic energy (TKE) with the Deardorff closure scheme was used (Deardorff 1972). The time-dependent TKE is solved by a prognostic equation and determines the mixing length and velocity scale. It consist of terms for advection, potential-kinetic energy conversion, shear production, dissipation and diffusion of TKE (Xue et al. 1995, 2000). The surface fluxes are responsible for the mass and heat exchange with the atmosphere. In ARPS they are computed by a stability and roughness-length dependent surface-flux model (Businger et al. 1971; Byun 1990). The fluxes are solved on the basis of the similarity theory of Monin and Obukhov. The surface momentum fluxes are defined by

$$
\begin{aligned}
\left.\tau_{13}\right|_{\text {surface }} & \equiv-\left[\overline{\rho u^{\prime \prime} w^{\prime \prime}}\right]_{\text {surface }}=\rho C_{d m} V u, \\
\left.\tau_{23}\right|_{\text {surface }} & \equiv-\left[\overline{\rho v^{\prime \prime} w^{\prime \prime}}\right]_{\text {surface }}=\rho C_{d m} V v,
\end{aligned}
$$

involving the drag coefficient $C_{d m}$ and the wind speed $V$, with components $u$ and $v$. The sensible and latent heat fluxes that account for heat exchange are described by

$$
\begin{aligned}
& H=\bar{\rho} C_{d h} C_{p} V\left(T-T_{s}\right), \\
& L E=L\left(E_{g}+E_{t r}+E_{r}\right),
\end{aligned}
$$

with the sensible and latent heat flux $H$ and $L E$, the heat exchange coefficient $C_{d h}$, the air temperature $T$ taken at the first level above ground and the ground surface temperature $T_{s}$. Consequently, the direction of the sensible heat flux is dependent on the temperature gradient near the surface. The latent heat flux is the sum of the evaporation of the soil surface $E_{g}$, the transpiration $E_{t r}$ and the fluxes from canopy water evaporation $E_{r}$.

In the present simulations the surface fluxes are calculated with stability-dependent drag coefficients and the bulk Richardson number as the stability parameter. For more details, see Xue et al. (1995, 2001). Soil-model general surface characteristics such as soil and vegetation types are provided by a force-restore two-layer soil and vegetation model (Noilhan and Planton 1989). It solves five prognostic equations for the soil temperature and soil moisture, where the vertical thickness of the soil layer is separated into a thin upper layer $(0.01 \mathrm{~m})$ and a deep layer $(1 \mathrm{~m})$. The surface layer interacts with the atmosphere, affecting its temperature, whereas the deep layer acts as a temperature reservoir affecting its thermal energy rather slowly. The input parameters for the soil type and the vegetation is based on USDA (United States Department of Agriculture) textural classes. ARPS provides 13 soil types (including water and ice) and 14 vegetation classes. Each run in the current study is initialised with loam and rain forest considering the conditions in Ecuador. The radiative cooling (see Fig. 1) necessary for the thermally driven flow is considered through atmospheric radiation transfer parametrisations. It is the primary force of the heat energy budget (5) and includes the net radiation, sensible heat flux and ground heat flux into the surface. The net radiative flux is given by

$$
R_{n}=R_{s w}\left(1-\alpha_{g}\right)+\epsilon_{g}\left(R_{A}-\sigma T_{s}^{4}\right),
$$

with the shortwave radiation $R_{s w}$, albedo $\alpha_{g}$, ground surface emissivity $\epsilon_{g}$, incoming longwave radiation $R_{A}$ and emitted longwave radiation from the ground surface $\sigma T_{s}^{4}$ with $\sigma$ for the Stefan-Boltzmann constant. If $R_{s w}$ becomes zero and the second term becomes larger, the net radiation becomes negative. 


\section{Results}

The simplified terrain models presented above have been used to examine the development and modification of an idealised katabatic flow as a result of different topographical geometries. Potential temperature distributions (colour) and wind field patterns (vectors) show general characteristics of the cold drainage air. With the ground surface fluxes, the driving force of the flow is illustrated. In order to demonstrate the impact of slope geometry on the occurrence of the flow, horizontal divergence fields and mass fluxes will be discussed in the context of flow confluence.

\subsection{Development of Katabatic Flows}

Figure 4 shows the evolution of the katabatic flow along a simple slope in a vertical crosssection as a function of the potential temperature (colours) and wind field distribution (vectors). In the beginning the potential temperature is horizontal stratified, changing to a slope-parallel distribution during the simulation. The decrease in air temperature develops first in the lower atmosphere and generates a temperature gradient to the ambient air at the same height. This process produces a temperature inversion near the ground, i.e. a katabatic layer as seen in Fig. 1. At the same time, the horizontal thermal gradient causes temperature advection, balancing the energy budget. Shortly after the start of the simulation, air temperature decreases by 1 to $299 \mathrm{~K}$ (Fig. 4a). The heat transfer is balanced by the temperature advection of cold air flowing down the slope and a growing inversion layer. The cold drainage air accumulates at the foot of the slope, forming a cold pool. In the ongoing simulation, the katabatic layer grows through the continuous cooling of the surface (Fig. 4b). The air temperature adjacent to the ground cools by an additional 2 to $297 \mathrm{~K}$ after $6900 \mathrm{~s}$. When the cold air arrives at the lateral boundary of the domain, it converges and is also propagated to upper layers. The wind vectors in Fig. 4 show a typical katabatic flow structure. Driven by an increasing buoyancy deficit the velocity of the katabatic flow increases with increasing slope length. The wind speed grows linearly in time until it reaches its maximum value of $5.8 \mathrm{~m} \mathrm{~s}^{-1}$ after $6900 \mathrm{~s}$ simulation time. Typical characteristics of katabatic flows are displayed on Fig. 5, showing the vertical profile of the potential air temperature, the wind velocity in the $u$-direction and the TKE in the centre of the slope. The potential temperature shows the evolution of a positive temperature gradient in the lower atmosphere with $3 \mathrm{~K}\left(100 \mathrm{~m}^{-1}\right)$. Above this inversion, the temperature profile undergoes a transition into an isothermal state that separates the katabatic layer from the free atmosphere. At this height, the buoyancy term is zero and the temperature adjacent to the ground equals the temperature of the ambient air at the same height. The wind profile forms the typical jet-like profile of a downslope flow shown in Fig. 1 with maximum wind speeds $\left(5.8 \mathrm{~m} \mathrm{~s}^{-1}\right)$ near the ground level, where the influence of the positive temperature gradient is strongest. Above and below this level, the velocity decreases because of increasing ground friction (below) and a decreasing positive temperature gradient (above). At higher levels, the latter leads to a decline in wind speeds to values around zero. In addition to mechanical turbulence induced by ground friction, the vertical wind shear is the second main source of TKE in a stable atmosphere such as this. The maximum of the TKE is near the maximum of the mean wind speed and reaches values of $0.16 \mathrm{~m}^{2} \mathrm{~s}^{-2}$ at levels where the vertical wind shear has its maximum (Horst and Doran 1986; Heilman and Takle 1991).

A comparison of the strength of the katabatic layer with an estimation of the Manins and Sawford hydraulic model (Manins and Sawford 1979) (Fig. 1) has been made to show that 
Fig. 4 Vertical cross-section ( $x z$ plots from $x=3.0 \mathrm{~km}$, $y=15.0 \mathrm{~km}$ and $x=17.0 \mathrm{~km}$, $y=15.0 \mathrm{~km}$ ) of the potential temperature (contour, K) and the wind field in $u-w$ direction (vectors, $\mathrm{m} \mathrm{s}^{-1}$ ) of SLP simulation for timesteps of a 3600s and b 6900s
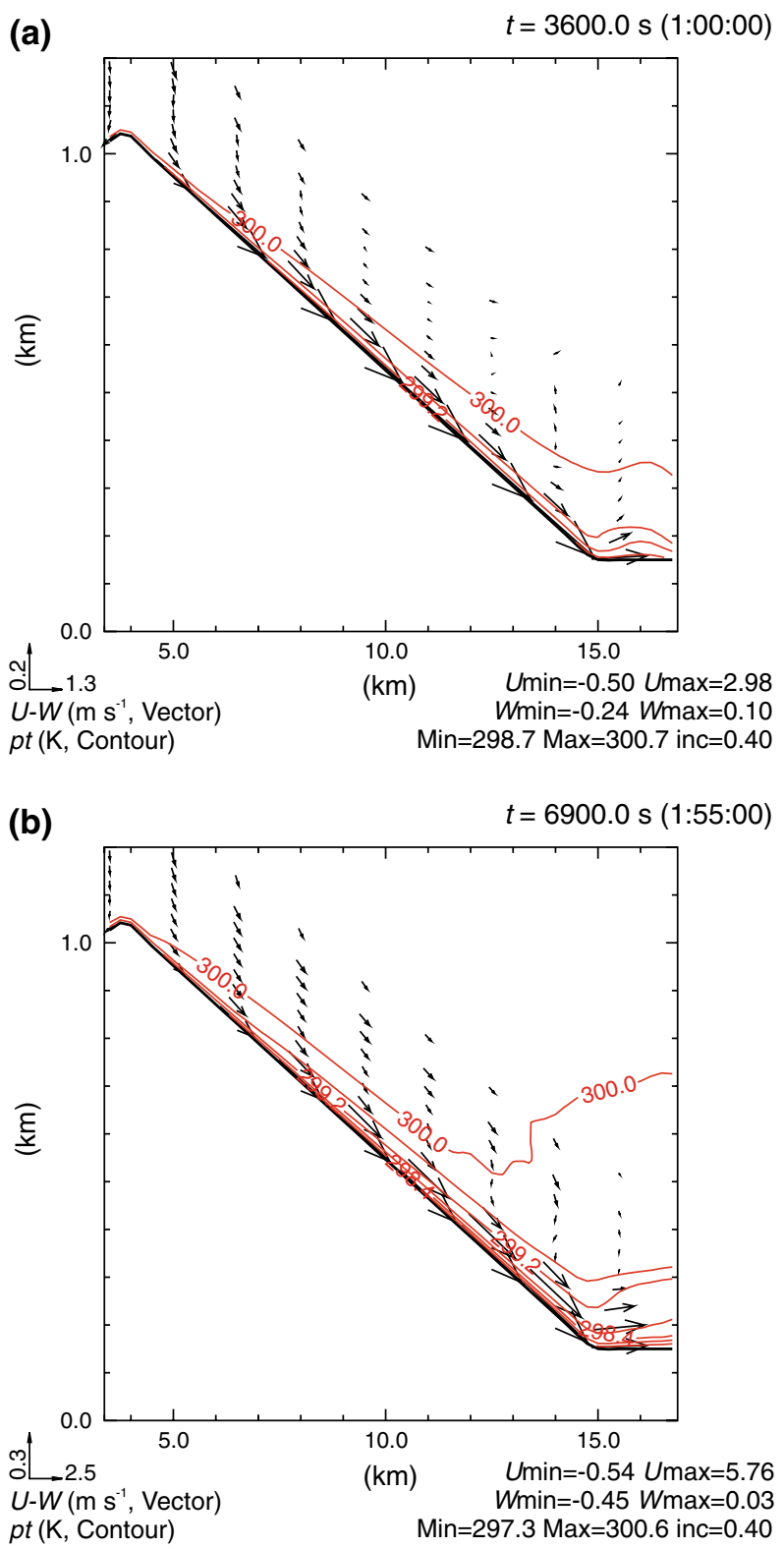

the vertical resolution does not affect the flow. Their model describes the depth $h$ as a function of slope distance $s$ and slope angle $\alpha$ with the entrainment coefficient $E$ and is defined as follows (see Horst and Doran 1986):

$$
\begin{aligned}
& h=0.75 E s, \\
& E=0.05(\sin \alpha)^{2 / 3} .
\end{aligned}
$$



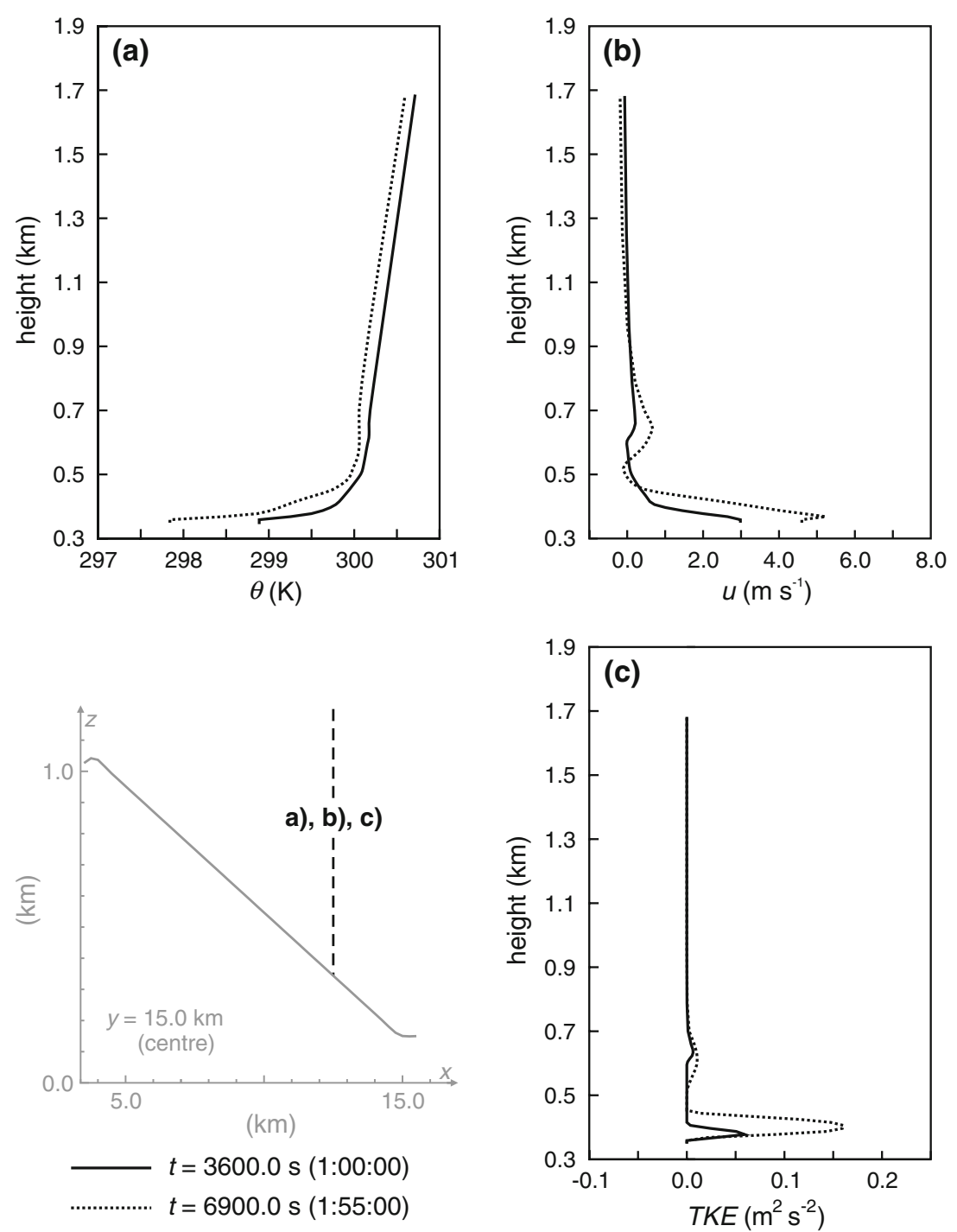

Fig. 5 Profiles of a the potential temperature $(p t)$, $\mathbf{b}$ the wind vector $(u)$ and $\mathbf{c}$ the turbulent kinetic energy (TKE) for timesteps of 3600 and $6900 \mathrm{~s}$ taken at $x=12.5 \mathrm{~km}$ and $y=15.0 \mathrm{~km}$

After this calculation the simulated katabatic layer is supposed to achieve a depth of $88 \mathrm{~m}$. Compared to the simulation results in Fig. 4, a depth of $121 \mathrm{~m}$ is obtained. Thus, our results of an idealised katabatic flow with the model set-up presented above approximates the estimated flow depth after the Manins and Sawford model. With a higher vertical resolution near the surface, it could be improved. But as the focus of this study is on the modification of the flow by topographical configurations, the outcome is sufficient and further adjustments were not considered necessary.

The driving mechanism of the katabatic flow is the buoyancy deficit, which develops due to radiation divergence (Eq. 5) associated with the ground heat fluxes (Eqs. 1-4) resulting 
from mechanically induced TKE and the latent and sensible heat fluxes. ARPS solves the surface fluxes responsible for the cooling of the surface on the basis of the similarity theory (Eq. 1 and 2). The soil temperature reduces to a value below the adjacent air temperature followed by the sensible heat flux (Eq. 3) from the atmospheric boundary layer to the earth surface balancing the heat loss. The surface acts as a sink for the thermal energy. The result is a cooling of the lower atmosphere and a development of a positive temperature gradient. A negative net radiation $\left(R_{n}\right)$ was observed during the simulation (Fig. 6), which indicates that the second term on the right-hand side of Eq. 5 is overbalanced. In the first hour, the net radiation decreases slightly, but remains constant afterwards at values around $100 \mathrm{~W} \mathrm{~m}^{-2}$. Hence, the buoyancy deficit is determined by the flow velocity and the slope angle. The sensible heat flux $H$ in the first hour of the simulation is almost zero, indicating less development, but afterwards $H$ becomes negative as well and stays constant throughout the simulation. So an energy flux from the atmosphere to the surface layer exists (Fig. 6). The atmospheric boundary layer is constantly cooled, as indicated by the net radiation and ground surface fluxes, and cold air is constantly transferred to the upper layers. Thus, the temperature deficit between the atmosphere and the surface decreases, causing a constant sensible heat flux from the atmosphere to the surface. The katabatic flow is sustained as long as the net radiation is negative.

The distribution of the heat energy fluxes in Fig. 6 shows the thermally driven mechanism of the downslope flow. Correlated with the temperature and windfield patterns in Fig. 4, their profiles in Fig. 5 and the estimation of the katabatic layer, one can conclude that ARPS produces feasible katabatic flows with chosen initial values and model set-up.

The cold drainage flow into a uniform valley (VAL), and into a valley with an additional along-side inclination (VAL2), was simulated as well. The VAL terrain model consist of two identical slopes, which have the same slope angle as SLP presented above. Due to several studies of katabatic flows along simple valleys, the results are summarised and the simulations not shown. As expected, an accumulation of the cold drainage air occurs in the VAL case

Fig. 6 The heat energy fluxes in $\mathrm{W} \mathrm{m}{ }^{-2}$ with the net radiation $\left(R_{n}\right)$, the sensible heat flux $(H)$, the latent heat flux $(L E)$ and the ground heat flux $(G)$ as a function of simulation time between 0 and $4 \mathrm{~h}$ taken at $x=12.5 \mathrm{~km}$ and $y=15.0 \mathrm{~km}$

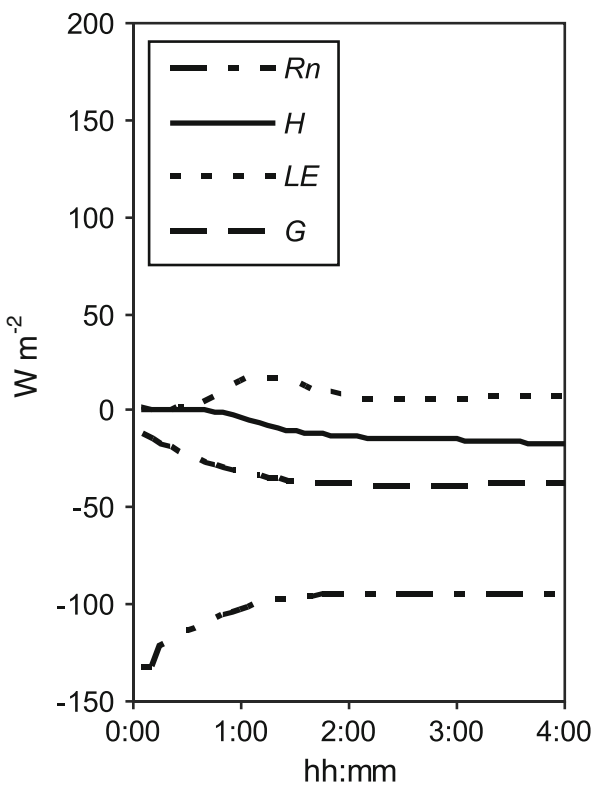


due to the lack of an along-valley inclination. The valley cross-flow increases to maximum values around $3.6 \mathrm{~m} \mathrm{~s}^{-1}$. Its values are minor compared to SLP due to the converging flow from the sidewalls with resulting upward motion. With an additional along-valley inclination, the cold drainage air is able to develop as an outflow, which obtains maximum velocities of approximately $1.8 \mathrm{~m} \mathrm{~s}^{-1}$. Compared to previous studies, (e.g., Doran et al. 1990a), the katabatic flow shows similar dynamics, e.g. the inversion depth down the valley is lower than at the higher sidewalls, which produces smaller flow velocities.

\subsection{Impact of Topography}

The impact of the topography on the occurrence of katabatic flows regarding its confluence is demonstrated with the terrain models BSN and BSNV (Fig. 3). BSN represents the first approximation of the concave-lined Andean terrain forming a basin in the target area. With potential temperature (colour) and corresponding wind field (vectors) patterns, the regime of the cold drainage air is indicated. Horizontal divergence fields illustrate the confluence and mass contribution inside the basin. Finally, BSNV describes the Andean orography with its complex drainage system. The impact of several mountain tops and a draining valley system, as it appears in the target area, on katabatic flows is examined. Also, horizontal divergence fields and mass changes show the influence of the katabatic flows.

\subsubsection{Basin}

For the analysis of the confluence of the katabatic flow, we begin with a uniformly concave curved slope creating a basin. The following Figs. 7, 8 and 9 show the results of the simulation to a height of $50 \mathrm{~m}$ above ground. In Fig. 7 the general behaviour of the flow is shown on the basis of the potential temperature distribution (colour) and the wind field patterns (vectors) at time step $14,400 \mathrm{~s}$.

A basic katabatic flow generated by radiative cooling has developed. The cold drainage air flows down the curved slope; velocity increases with slope distance. A large

Fig. 7 Horizontal cross-section ( $x y$ plot at $z=50 \mathrm{~m}$ above ground level) of the potential temperature (shaded, K) and the wind field in the $u-v$ direction (vectors, $\mathrm{m} \mathrm{s}^{-1}$ ) of BSN simulation for a timestep of $14,400 \mathrm{~s}$

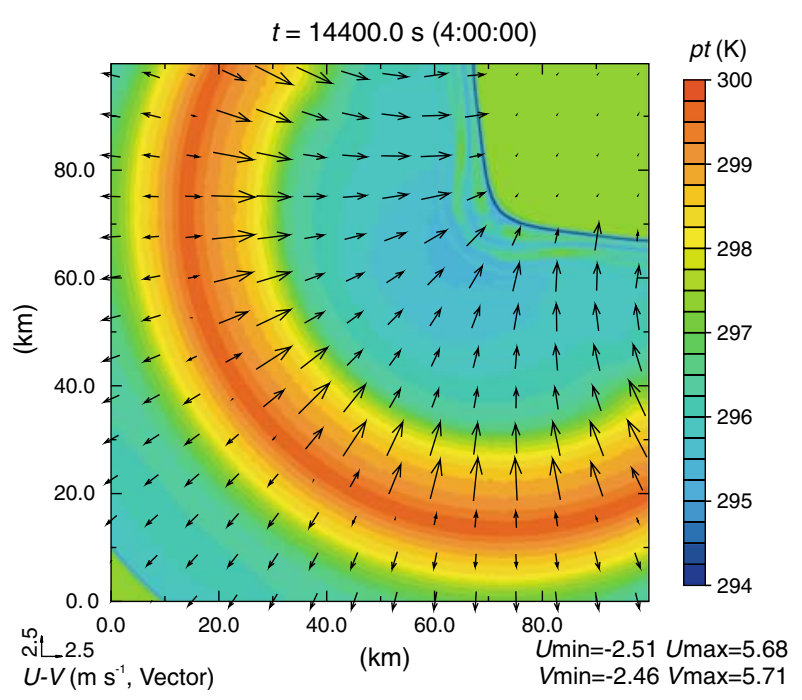




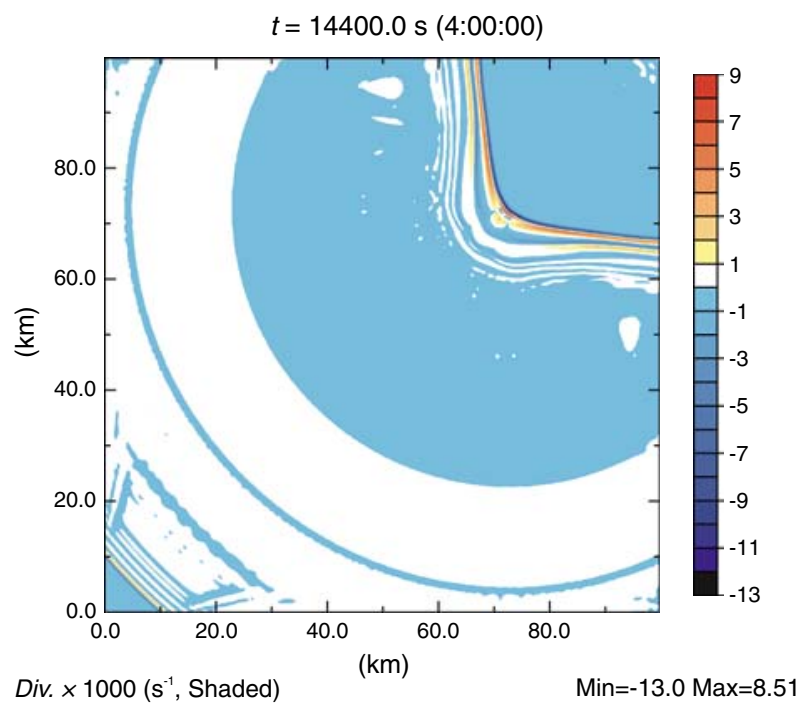

Fig. 8 Horizontal cross-section ( $x y$ plot at $z=50 \mathrm{~m}$ above ground level) of the divergence field (shaded, $\mathrm{s}^{-1}$ amplified by a factor of 1000) of BSN simulation for a timestep of $14,400 \mathrm{~s}$

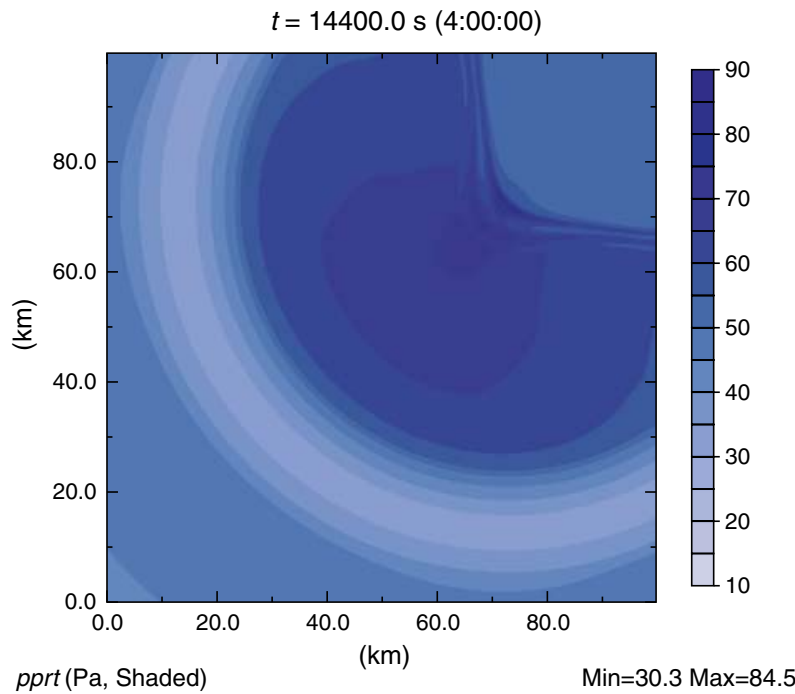

Fig. 9 Horizontal cross-section ( $x y$ plot at $z=50 \mathrm{~m}$ above ground level) of the pressure perturbation field (shaded, Pa) of BSN simulation for a timestep of $14,400 \mathrm{~s}$

horizontal temperature gradient causes the propagation of the air throughout the basin. Along the curved slope, the drainage air rapidly accelerated with distance to its maximum values around $5.8 \mathrm{~m} \mathrm{~s}^{-1}$ as seen in SLP. At the foot, the drainage air decelerates to a minimum around $2 \mathrm{~m} \mathrm{~s}^{-1}$. This is the result of the buoyancy deficit's decreasing influence. Driven by a large horizontal temperature gradient, the cold air advances further into the basin. There, as expected, the terrain configuration forces the flow to confluence, as shown by the accumulation of cold air in the centre of the basin with minimum potential temperature of $294.75 \mathrm{~K}$. 
Inside the basin, the velocity remains nearly constant until it reaches the convergence zone, where the temperature gradient reaches its maximum. There the velocities rise again to reach maximum values of around $4 \mathrm{~m} \mathrm{~s}^{-1}$.

The confluence of the horizontal wind field can be illustrated in terms of horizontal divergences. In doing so, negative values describe convergences and positive values represent divergence of the horizontal wind field. The results in Fig. 8 are shown with an amplification factor of 1000. Inside the basin, a continuous horizontal convergence has developed, until the cold air reaches its maximum. In this zone, an explicit divergence line with maximum $8.5 \mathrm{~s}^{-1}$ alternates with an explicit convergence line of $13 \mathrm{~s}^{-1}$, indicating frontal structures. However, to analyse the confluence of the cold drainage air due to the shape of terrain, we investigate the mass contribution as well. Since a confluence of the horizontal wind field near the surface is closely linked to changes in the mass field, the perturbation of pressure (pprt) is displayed in Fig. 9. At the slope, the pressure increases uniformly with distance by around $40 \mathrm{~Pa}$, whereas inside the basin the largest perturbation is concentrated with a maximum 84.5 Pa. Most of the mass contribution is located there, particularly in the middle of the convergence zone. An accumulation of mass has taken place, which strengthens the issue of confluencing katabatic flows forced by the concave shape of the terrain configuration.

\subsubsection{Drainage System}

Finally, variations in the flow dynamics are analysed with a concave curved slope interrupted by several valleys generating a complex drainage system. The terrain model that was used describes the main features of the topography in the target area. The results of the simulation at a height of $50 \mathrm{~m}$ above the surface are displayed in Figs. 10, 11 and 12. The general occurrence is also shown in terms of the potential temperature distribution (colour) and wind vectors (Fig. 10). As in BSN, a general katabatic flow along the slopes has developed through radiative cooling. The cold drainage air flows down the mountain into various valleys and directly into the basin. At the valley floors, maximum cooling with a potential temperature of $294 \mathrm{~K}$ occurs. Forced by the inclination of the valleys, the cold surface air drains into the basin. In their exit regions the cold air can spread, but as it advances further into the basin it undergoes confluence, forced by the concave topographical geometry. In BSN, a large horizontal temperature gradient was generated, causing this propagation.

The velocities of the katabatic flow differ slightly from BSN as a result of the drainage system. Along the slopes the flow accelerates with increasing distance to a maximum of $5.8 \mathrm{~m} \mathrm{~s}^{-1}$ as with BSN and SLP. Inside the basin the flow too decelerates due to the decreasing influence of the buoyancy deficit, but not consistently. The impact of the drainage system is evident. The draining valleys add an additional driving force, accelerating the flow. With increasing distance along the valley floors, the cold air velocities increased to values around $9.5 \mathrm{~m} \mathrm{~s}^{-1}$. This is a combined result of the inclination and the channelling effect of the valleys. In their exit regions, the flow obtains a further acceleration to its maximum values of $10.1 \mathrm{~m} \mathrm{~s}^{-1}$. The flow decreases with increasing distance from the exit regions, but accelerates again to $4 \mathrm{~m} \mathrm{~s}^{-1}$ when it is close to the confluence zone where the temperature gradient reaches its maximum.

The horizontal divergence field (values are amplified by a factor of 1000) and pressure perturbation are also used to evaluate the confluencing katabatic flow (Fig. 11). The uniform convergence is divided by additional divergence patterns at the exit region of each valley caused by the cold drainage air advancing into the basin. The convergences reach values around $5.8 \mathrm{~s}^{-1}$, whereas the divergences achieves $4 \mathrm{~s}^{-1}$. Inside the basin the convergences decrease to values around $1 \mathrm{~s}^{-1}$, as in $\mathrm{BSN}$, divided by calm regions. In the valleys the flow 
Fig. 10 Horizontal cross-section ( $x y$ plot at $z=50 \mathrm{~m}$ above ground level) of the potential temperature (shaded, K) and the wind field in $u-v$ direction (vectors, $\mathrm{m} \mathrm{s}^{-1}$ ) of BSNV simulation for a timestep of $14,400 \mathrm{~s}$

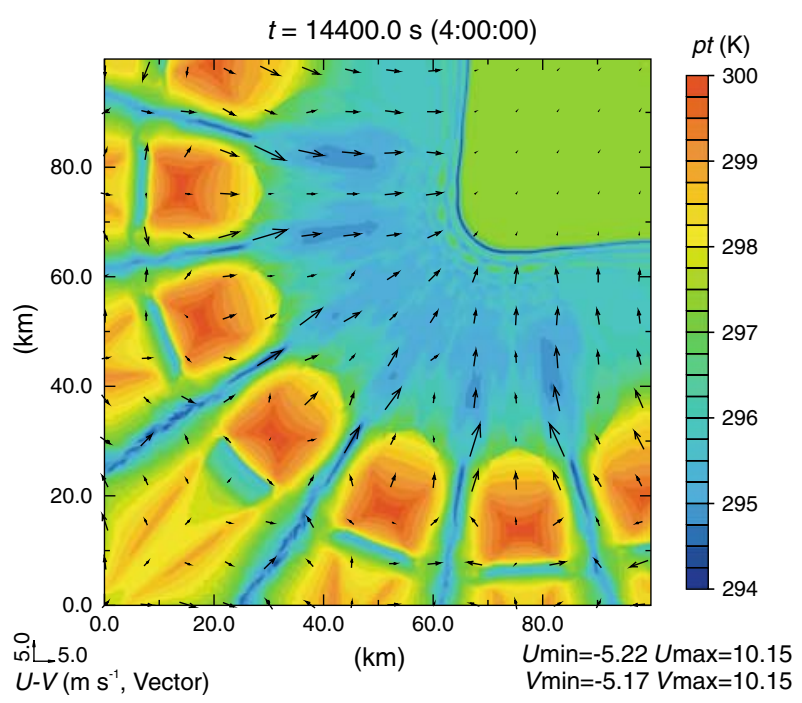

$t=14400.0 \mathrm{~s}(4: 00: 00)$

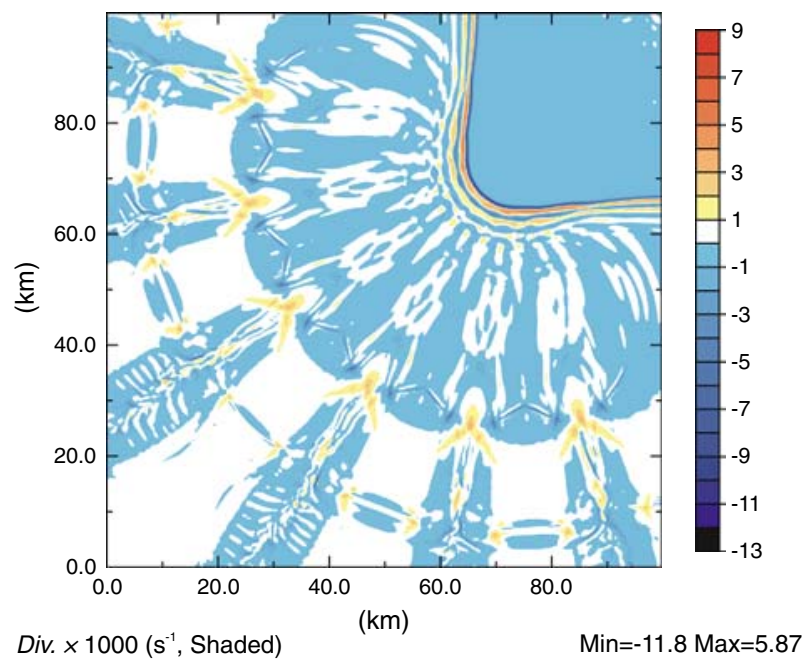

Fig. 11 Horizontal cross-section ( $x y$ plot at $z=50 \mathrm{~m}$ above ground level) of the divergence field (shaded, $\mathrm{s}^{-1}$ amplified by a factor of 1000) of BSNV simulation for a timestep of $14,400 \mathrm{~s}$

from the slopes initially converges, inducing an along-valley flow afterwards, as seen in the divergence field.

The corresponding pressure perturbation (pprt) field (Fig. 12) shows more details of the confluence of the cold drainage air mass. It is evident that the valley drainage into the basin contributes the greatest increase in mass, with a maximum of $77.2 \mathrm{~Pa}$, which is created by the converging air from the surrounding mountain tops. Inside the basin, the pressure rises to 67.5 Pa, but is unevenly allocated. However, the greatest mass increase occurs in the centre of the basin indicating the confluence of the cold drainage air due to the terrain configuration. 
Fig. 12 Horizontal cross-section ( $x y$ plot at $z=50 \mathrm{~m}$ above ground level) of the pressure perturbation field (shaded, $\mathrm{Pa}$ ) of BSNV simulation for a timestep of $14,400 \mathrm{~s}$

Fig. 13 Vertical cross-section ( $x z$ plot from $x=50.0 \mathrm{~km}$, $y=50.0 \mathrm{~km}$ to $x=79.0 \mathrm{~km}$, $y=79.0 \mathrm{~km})$ of the divergence field (shaded, $\mathrm{s}^{-1}$ amplified by a factor of 1000) and the wind field in $u-w$ direction (vectors, $\mathrm{m} \mathrm{s}^{-1}$ ) of BSNV simulation for a timestep of $14,400 \mathrm{~s}$
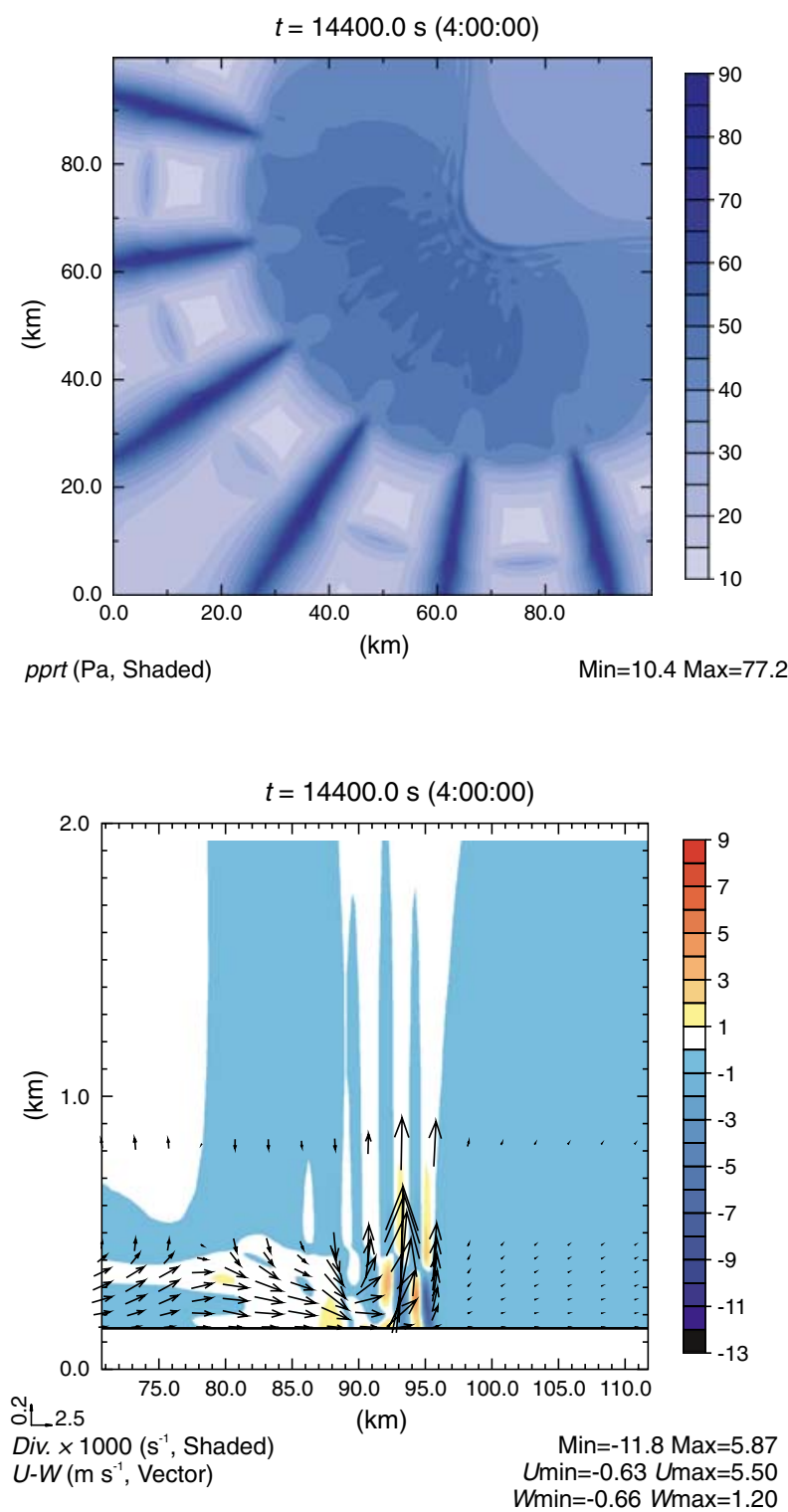

To take a closer look at this convergence zone, a cross-section through its middle has been made. Convergence of the horizontal wind field near the surface not only implies mass contribution, it is also related to vertical motion. Accordingly, the vertical divergence field overlayed with wind vectors in the $u-w$ direction is shown in Fig. 13. The ambient atmosphere is calm, without any vertical motions, as already seen in previous figures. However, the region of interest shows an alternating convergence and divergence line associated with upward (maximum $1.2 \mathrm{~m} \mathrm{~s}^{-1}$ ) and downward (maximum $0.66 \mathrm{~m} \mathrm{~s}^{-1}$ ) motion, indicating a deformed wind field, which points to a frontal zone (Eliassen 1959). 


\section{Discussion}

As expected, the geometry of topography has strong effects on the general behaviour of katabatic flows. Particularly the concave terrain configuration shown herein demonstrates the topography's influence regarding the confluence of the cold drainage air over low terrain. With the simplified terrain models BSN and BSNV (Fig. 3), the main orographical features of the Andes of southern Ecuador/northern Peru are covered and are used to explore the occurrence and modification of the cold drainage air.

First, BSN as a uniformly concave terrain configuration was used to show the principle modification of a general katabatic flow concerning its confluence. The results of the simulations (Fig. 7) illustrate the common development of a thermally induced downslope with increasing wind velocity along the slope distance. The cold surface air drains into the basin, where it consistently advances through the basin as a result of the regular slope configuration. Forced by the topography, a convergence zone following the concave terrain line developed.

Interrupting the basic geometry of BSN with several valleys forming a complex drainage system into the basin, the complex structure of the Andean orography has been captured. Just as with BSN, BSNV was used to examine the confluence of the katabatic flow, but with a marked drainage system. As seen in Fig. 10, a steady flow was generated by the terrain configuration. The results of the simulation also show the development of a katabatic flow. However, this time a downslope motion occurs along every existing slope of the terrain model separating the regular inflow of cold air and its steady confluence. This follows the drainage system, induced by the six large valleys, causing variations of the cold air inflow. Thus, in the exit region the cold drainage air propagates faster into the basin as the air from the slopes directed towards the basin. Compared to the continuous concave line terrain, an unsteady inflow of cold air developed due to an irregular configuration of topography. The effect of slope angle and slope distance on the occurrence of katabatic flows, as described in Manins and Sawford (1979) is demonstrated by the various slope angles forming the drainage system, as shown in Fig. 1.

An analysis of the horizontal divergence field in BSN and BSNV as shown in Figs. 8 and 11 contributed to this result. In BSN, the basin is calm and undisturbed with a permanent convergence of approximately $2 \mathrm{~s}^{-1}$ until it reaches the zone of maximum horizontal temperature gradient. There, the cold drainage air converges with the less cold air from the basin. However, this convergence zone is arranged linearly following the concave lined terrain, and caused the mentioned acceleration in wind speed in the katabatic flow (Parish 1982; Bromwich and Kurtz 1984). With the perturbed pressure distribution, we can take a closer look to the confluence of cold air. As seen in Fig. 9, the greatest mass increase is concentrated in the middle of the basin, which indicates a confluencing katabatic flow on the basis of a concave lined slope.

The concave curved slope is interrupted by an extensive drainage system, which has consequent effects on the mass contribution to the basin (see Fig. 12). Since the valleys add an additional driving force, which generates an increase in the velocity compared to the downslope flowing directly into the basin, the inflow is discontinued. It is evident, especially in the exit region of each valley, that this acceleration leads to a modification of the cold air mass distribution. At the exit regions the flow can spread, which is made clear by the horizontal divergence field of the flow. The results are alternating patterns of divergences and convergences in the basin, which differ clearly from BSN. However, despite these variations in cold surface flow dynamics, a net confluence of the flow developed, as seen by the mass contribution in Fig. 12. As in BSN, the greatest mass increase took place in the centre 
of the basin, although the mass contribution is less due to the drainage system. A convergence line following the basic structure of the concave terrain line also developed, just as in BSN.

The vertical cross-section in Fig. 13 shows the formation of a typical frontal zone with upward and downward motions. However, the vertical velocities are rather low, which results from insufficients moisture in the atmosphere. It must be pointed out that the simulations were primarily intended to show the occurrence of katabatic flows and to demonstrate their confluence as a result of the impact of terrain geometries. Nevertheless, the basic structures of a surface front are already visible and will be further analysed in future work with regard to the second hypothesis stated above.

\section{Summary and Conclusions}

In this study the mesoscale model ARPS was used to investigate the impact of different terrain shapes on a katabatic flow in an idealised case study. The main subject of the analysis is the confluence of the flow due to a concave-lined terrain configuration. The target area is located at the eastern Andean slopes of southern Ecuador and the northern Peruvian Amazon basin. Due to the very steep slopes and valleys of the Andes, five different simplified terrain models representing the main characteristics of the topography in this area were used.

Using a simple slope model, it could be shown that a katabatic flow was generated. With the resulting potential temperature and wind field patterns the typical characteristics of cold drainage flows, such as the formation of a katabatic layer and the jet-like wind profile, were illustrated. Furthermore, it could be demonstrated that the surface heat fluxes, along with the associated cooling of the surface layer, act as main drivers for the katabatic flow. Hence, a typical thermally driven flow developed.

The impact of the topographical geometry with an uniformly concave-lined slope on katabatic flows was shown regarding its confluence. The cold drainage air was forced by the shape of the terrain to propagate into the centre of the basin. There it produced a large horizontal temperature gradient inducing a convergence line. As a result of the slope geometry the most pronounced horizontal divergence developed in the centre of the basin.

A complex drainage system captures the Andean orography of the target area. It changes the uniform concave slope structure with several valleys and mountain tops forming a complex drainage system regime. The results of the simulation show that the continuous flow structures of BSN were interrupted by the draining valleys, but the general flow behaviour was sustained. The effect of these properties is that, although no regular inflow of katabatic flow occurs due to various slope angles and distances, the cold drainage air confluenced because of the general concave geometry of the topography.

The results of the study at hand verify the initial hypothesis that nocturnal drainage air from slopes and valleys confluences due to a concave topography. A persistent thermally driven flow advances through the basin, generating a convergence line that is largest in the centre. Thus, further work is required to verify the second hypothesis stated at the beginning, i.e. the formation of convective clusters due to interaction in confluencing cold drainage air, shown herein with the warm moist air from the Amazon basin.

Acknowledgements The authors are indebted to the German Research Foundation (DFG) for the funding of the work in the scope of the Research Unit RU816 'Biodiversity and Sustainable Management of a Megadiverse Mountain Ecosystem in South Ecuador', sub projects B3.1 and Z1.1 (BE 1780/15-1, NA 783/1-1). 
Open Access This article is distributed under the terms of the Creative Commons Attribution Noncommercial License which permits any noncommercial use, distribution, and reproduction in any medium, provided the original author(s) and source are credited.

\section{References}

Ball FK (1956) The theory of strong katabatic flows. Aust J Phys 9:373-386

Bendix J, Rollenbeck R, Reudenbach C (2006) Diurnal patterns of rainfall in a tropical Andean valley of southern Ecuador as seen by a vertical pointing k-band doppler radar. Int J Climatol 26:829-846

Bendix J, Trachte K, Cermak J, Rollenbeck R, Nauss T (2009) Formation of convective clouds at the foothills of the tropical eastern Andes (south Ecuador). J Appl Meteorol 48:1682-1695

Bromwich DH, Kurtz DD (1984) Katabatic wind forcing of the terra nova bay polynya. J Geophys Res 89:3561-3572

Businger JA, Wyngaard JC, Izumi Y, Bradley EF (1971) Flux-profile relationship in the atmospheric surface layer. J Atmos Sci 28:181-189

Byun DW (1990) On the analytic solutions of flux-profile relationships for the atmospheric surface layer. J Appl Meteorol 29:652-657

Chow FK, Weigel AP, Street RL, Rotach MW, Xue M (2006) High-resolution large-eddy simulations of flow in a steep alpine valley. Part I. Methodology, verification, and sensitivity experiments. J Appl Meteorol Climatol 45:63-86

Clements WE, Archuleta JA, Hoard DE (1989) Mean structure of the nocturnal drainage flow in a deep valley. J Appl Meteorol 28:457-462

Deardorff JW (1972) Parameterization of the planetary boundary layer for use in general circulation models. Mon Weather Rev 100:93-106

Defant F (1949) Zur Theorie der Hangwinde, nebst Bemerkungen zur Theorie der Berg- und Talwinde. Arch Meteorol Geophys Bioklim A 1:421-450

Doran JC (1990) The effects of ambient winds on valley drainage flows. Boundary-Layer Meteorol 55: $177-189$

Doran JC, Horst TW, Whiteman CD (1990) The development and structure of nocturnal slope winds in a simple valley. Boundary-Layer Meteorol 52:41-68

Eliassen A (1959) On the formation of fronts in the atmosphere. In: Bolin B (ed) The atmosphere and the sea in motion. University Press, Oxford, pp 227-287

Fitzjarred DR (1984) Katabatic wind in opposing flow. J Atmos Sci 41:1143-1158

Fleagle RG (1950) A theory of air drainage. J Meteorol 7:227-232

Garrett AJ (1983) Drainage flow prediction with a one-dimensional model including canopy, soil and radiation parameterizations. J Clim Appl Meteorol 22:79-91

Gudiksen PH, Leone MJJ, King CW, Ruffieux CW, Neff WD (1992) Measurments and modeling of the effects of ambient meteorology on nocturnal drainage flows. J Appl Meteorol 31:1023-1032

Gutman LN (1983) On the theory of the katabatic slope wind. Tellus, A Dyn Meteorol Oceanogr 35:213-218

Heilman WE, Takle ES (1991) Numerical simulation of the nocturnal turbulence characteristics over Rattlesnake mountain. J Appl Meteorol 30:1106-1116

Horst TW, Doran JC (1986) Nocturnal drainage flow on simple slopes. Boundary-Layer Meteorol 34:263-286

Klemp JB, Wilhelmson RB (1978) The simulation of three-dimensional convective storm dynamics. J Atmos Sci 35:1070-1096

Kondo J, Sato T (1988) A simple model of drainage flow on a slope. Boundary-Layer Meteorol 43:103-123

Lalaurette F, Andre JC (1985) On the integral modelling of katabatic flows. Boundary-Layer Meteorol 33:135149

Mahrt L (1982) Momentum balance of gravity flows. J Atmos Sci 39:2701-2711

Manins PC (1992) Vertical fluxes in katabatic flows. Boundary-Layer Meteorol 60:169-178

Manins PC, Sawford BL (1979) A model of katabatic winds. J Atmos Sci 36:619-630

McClatchey RA, Fenn RW, Selby JEA, Volz FE, Garing JS (1972) Optical properties of the atmosphere, 3rd edn. AFCRL-72-0497. Hanscom Air Force Base, Bedford, Massachusetts, 108 pp

Noilhan J, Planton S (1989) A simple parameterization of land surface processes for meteorological models. Mon Weather Rev 117:536-549

Parish TR (1982) Surface air flow over east Antarctica. Mon Weather Rev 110:84-90

Poulos G, Bossert JE, McKee T, Pileke RAS (2007) The interaction of katabatic flow and mountain waves. Part II. Case study analysis and conceptual model. J Atmos Sci 64:1857-1879

Prandtl L (1942) Stroemungslehre (flow studies). Vieweg und Sohn, Braunschweig, Germany, 648 pp 
Shapiro A, Fedorovich E (2007) Katabatic flow along a differentially cooled sloping surface. J Fluid Mech 571:149-175

Skyllingstad ED (2003) Large-eddy simulation of katabatic flows. Boundary-Layer Meteorol 106:217-243

Smith CM, Skyllingstad ED (2005) Numerical simulation of katabatic flow with changing slope angle. Mon Weather Rev 133:3065-3080

Thyer NH (1966) A theoretical explanation of mountain and valley winds by a numerical method. Arch Meteorol Geophys Bioklim A 15:318-348

Xue M, Droegemeier KK, Wong V, Shapiro A, Brewster K (1995) Advanced Regional Prediction System (ARPS) version 4.0 user's guide. Center for Analysis and Prediction of Storms, University of Oklahoma, $380 \mathrm{pp}$

Xue M, Droegemeier KK, Wong V (2000) The advanced regional prediction system (arps) — a multiscale nonhydrostatic atmospheric simulation and prediction tool. Part I. Model dynamics and verification. Meteorol Atmos Phys 75:161-193

Xue M, Droegemeier KK, Wong V, Shapiro A, Brewster K, Carr F, Weber D, Liu Y, Wang DH (2001) The advanced regional prediction system (arps) - a multiscale nonhydrostatic atmospheric simulation and prediction tool. Part II. Model physics and applications. Meteorol Atmos Phys 76:134-165

Yu Y, Cai XM (2006) Structure and dynamics of katabatic flow jumps: Idealized simulations. Boundary-Layer Meteorol 118:527-555 